\title{
Palm Oil Production in Malaysia: An Analytical Systems Model for Balancing Economic Prosperity, Forest Conservation and Social Welfare
}

\author{
Nickson E. Otieno',2, Xeuping Dai2, Daniele De Barba², Abbassi Bahman², Elise Smedbol2, \\ Marouan Rajeb², Lise Jaton² \\ ${ }^{1}$ National Museums of Kenya, Nairobi, Kenya \\ ${ }^{2}$ University of Quebec À Trois Rivières, Québec, Canada \\ Email: neotieno@yahoo.com
}

Received 2 January 2016; accepted 14 February 2016; published 17 February 2016

Copyright $(2016$ by authors and Scientific Research Publishing Inc.

This work is licensed under the Creative Commons Attribution International License (CC BY).

http://creativecommons.org/licenses/by/4.0/

(c) (i) Open Access

\section{Abstract}

Since the late 1950's, the Malaysian human population has nearly quadrupled, increasing pressure on natural resource exploitation to meet domestic needs and to earn foreign exchange from exports. Global demand for Malaysian palm oil in particular had steeply increased since the mid1970 s and by 2013 , the commodity was the leading foreign exchange earner. To fulfill and sustain this demand, the country's economy has steadily shifted bias towards production and associated value addition of palm oil products for export. However, as a consequence, many of Malaysia's natural tropical forests have been converted to palm oil farming resulting in loss of approximately $10,000 \mathrm{~km}^{2}$ of forest cover over the past twenty-five years, and biodiversity has been displaced or lost. To provide a deeper insight into the interplay amongst key interrelated environmental and socio-economic variables, and a forecast of possible future balance, we used a systems dynamism modeling tool, STELLA ${ }^{\mathrm{R}}$ (structural thinking, experiential learning laboratory with animation), to simulate and project how Malaysia could achieve a medium-term sustainable balance or optimization between palm oil production and forest conservation without compromising on human social welfare. The model consisted of four main modules (environmental, economic, social development and human welfare) each with component parameters, and interconnected by input and output loops. Model calibrations, testing and pre-runs involved existing official 30-year time-series datasets. Subsequently, four scenarios: Environmental conservation; Economic growth under increased global palm oil demand; Economy decline under decreased palm oil demand; and Control condition with little or no change, were selected for simulated projections of future possibilities. Simulation results showed that scenarios and variable interactions that reduce environmental 
damage would offer the best chance for optimizing the palm oil economy while also minimizing forest loss and promoting citizen social welfare.

\section{Keywords}

Palm Oil, Systems Modeling, Sustainable Development, Conservation, Malaysia

\section{Introduction}

Malaysia, a South-Eastern Asian country located near the equator, comprises two roughly equal regions: the Peninsular Malaysia and Malaysian Borneo. The multi-ethnic population is governed by a monarchical system. In the last 50 years, the Malaysian economy experienced strong growth, rising from USD 8.2 million in 1960 to USD 29.8 million in 2014 [1]. Despite this growth in national wealth, the majority of the population is poor and the economy relies heavily on the agricultural sector which accounts for three-quarters of household incomes [2]. In the 1970s, one fundamental objective of Malaysian Government's Economic Policy was to eradicate poverty by raising income levels and increasing employment opportunities [2]. Palm oil production which is currently the most significant agricultural export for the country, represents an important commodity that may be used as a vehicle for rural poverty eradication [3], particularly I light of the prevailing ideal climatic and edaphic conditions for its cultivation [4].

Malaysian palm oil exploitation began in 1917 [5], but had steeply grown since 1961 when the Federal Land Development Authority (FELDA) allocated 375 hectares specifically for the crop [6]. At the same time, the government encouraged a policy that replaced rubber oil fields by palm oil plantations in rehabilitated or newly opened area [3] with the dual aim of diversifying agricultural development and also enhancing the commercialization of the sector [5]. The Malaysian Palm Oil Council (MPOC) also developed strategies to place Malaysia as an international leader in the vegetable oils and fat market through promotional activities. Consequently, Malaysia became the world's leading exporter of palm oil until 1997 when it was surpassed by Indonesia in 2007 [6] (see Table 1).

Table 1. The world's 25 leading palm oil exporting countries. Estimates are for 2014 and in 1000 metric tonnes.

\begin{tabular}{|c|c|c|}
\hline Rank & Country & Export volume (metric tonned) \\
\hline 1 & Indonesia & 22,500 \\
\hline 2 & Malaysia & 17,200 \\
\hline 3 & Papua New Guinea & 640 \\
\hline 4 & Benin & 450 \\
\hline 5 & Guatemala & 405 \\
\hline 6 & Thailand & 400 \\
\hline 7 & Honduras & 300 \\
\hline 8 & Côte D’ivoire & 260 \\
\hline 9 & Colombia & 260 \\
\hline 10 & United Arab Emirates & 250 \\
\hline 11 & Ecuador & 240 \\
\hline 12 & Costa Rica & 160 \\
\hline 13 & EU-27 & 160 \\
\hline 14 & Egypt & 150 \\
\hline 15 & Singapore & 100 \\
\hline
\end{tabular}


Palm oil is a steady source of affordable edible and non-edible oils, bio-composites, nutritional and other pharmaceutical products. About $80 \%$ of palm oil products are edible while $20 \%$ are for non-edible use such as chemical manufacturing [5]. For instance, currently, palm oil accounts for about 5\% of the world's bio-diesel production [4].

Production of palm oil has increased significantly due to increasing global demand with major importers being India, China and the European Union [4]. Since 1990, the global consumption had quadrupled [6] and, according to Corley (2009) [7], the demand for edible vegetable oils was expected to double from present consumption by 2050. Assuming that all projected expansion of land under palm oil production is realized in major producing counties, the area under harvest could increase by 140\% from 2007 to 2050 [8]. This increase could be greater with the anticipated development of the palm oil industry as a major source of global biofuels [4]. The phenomenal growth in global production and demand for palm oil is attributable to three factors: the relatively lower cost of production compared to other major cash crops; the health benefits of edible vegetable oils rather than alternatives from animal products; and the wide variety, uses, versatility and applications of palm oil products and derivatives, ranging from domestic, industrial, medical and agricultural [9].

\section{Research Problem}

Although increase in palm oil exploitation brings many obvious economic advantages, the industry is also faced with a number or challenges and controversies. For instance it accounts for about 8\% of total Malaysian GDP [10]. However, while at the social level, an increase in production earnings should ideally translate to general reduction of poverty levels amongst the Malaysian population contribute to alleviation of poverty levels, the converse is in fact apparent [11] [12]. There are also concerns about the industry's impact on the environment as it is now estimated that the palm oil cultivation was responsible for loss of an estimated 1.1 million ha of the country's tropical rainforest cover between 1990 and 2005 alone [13]. Conversion of forest and other land use forms to palm oil production is further associated with pollution of water bodies (through application of fertilizers, insecticides and herbicides) as well as biodiversity loss [14]. In addition, although biofuel derived from palm oil can be used as an environmentally clean substitute to fossil fuel, there are large greenhouse gas emissions associated with the processing of such biofuels. It is estimated that converting rainforest into palm tree plantation to replace fossil fuel would result into emission of at least as much $\mathrm{CO}_{2}$ as the burning of fossil fuels [15].

The goal of this dynamic model project was to determine how Malaysia could strike a sustainable balance between palm oil production, rainforest conservation and promotion of social well-being. To achieve this, we employed a simulated interaction amongst a number of variables interacting over a period of 10 years in specific time steps, within the three main module themes: Social, Economics and Environment. The social welfare is used as a juxta-positional variable for conjoining as well as gauging the interactions of the modules.

\section{Methods}

\subsection{Study Area}

Malaysia is a south-east Asian country with approximately 330,000 $\mathrm{km}^{2}$ of land cover and $1190 \mathrm{~km}^{2}$ and lies between $02^{\circ}-30^{\circ} \mathrm{N}$ and $112^{\circ}-30^{\circ} \mathrm{E}$. The elevation ranges from 0 to $4100 \mathrm{~m}$ above sea level. The country is characterised by a tropical humid climate with diurnal temperatures up to around $24^{\circ} \mathrm{C}-28^{\circ} \mathrm{C}$ year-round and minimum night-time temperatures averaging $20^{\circ} \mathrm{C}$. The 2015 human population estimate is 30,866,000 with an overall density of 92 per 5 sons $/ \mathrm{km}^{2} 70 \%$ of the population living in urban areas. Malaysia has a Total Gross Domestic Product estimated at US\$ 800 billion with a capita income of US\$25,833. Although as an emerging economy, Malaysia's economy is becoming rapidly industrial, the country still depends heavily on agricultural commodity exports with palm oil the main agricultural foreign exchange earner. This is due to a steady rise in global demand for palm oil as substitute for classical animal and other saturated oils in an increasingly healthconscious world. Malaysia has a result emerged as the leading exporters of palm oil in the world, with large tracks of natural tropical forest being increasingly converted to palm oil fields. Malaysia is also considerably rich in biodiversity due a largely favourable but diverse tropical climate that supports high diversity and endemism of flora and fauna. It therefore hosts several species of mammals including tiger and primates as well as birds, reptiles, amphibians, plants and aquatic resources. Conversion of natural forest to farmland, coupled with illegal hunting has been exerting increasing pressure on wild forest species, particularly the tiger and primates. Although 
palm oil farming is highly developed in terms of mechanization and systematization, majority of workers are still low-skill, low-income people. Intensification of these farms, together with heavy input of agro-chemicals pose additional challenges to environmental conservation and therefore sustainable agriculture.

The modeling was performed in Stella Modeling software (version 10.0.3, ISEE Systems, Inc.). The various selected parameters and variables were framed within three main modules (environment; economy; social development) and interactions tested within specific spatial and temporal framework scales. Subsequently, interactivity amongst all variables was tested across the three modules for overall responses. Testing and calibration was done using existing published data and official metric and related reports produced by the Government of Malaysia's Department of Agriculture. Finally, modeling and projections were achieved through simulations of parameters, underpinned within four scenarios: environmental conservation; increased palm oil demand; decreased palm oil demand and; control. The whole model's conceptual structure is outlined in Figure 1.

\subsection{Calibration, Temporal and Spatial Scales}

With the aim of representing the national dynamics of the palm oil exploitation, the model considered Malaysia as a whole as the spatial scale for all variables with the exception of the human population which was the only one distinguished as either rural or urban. A scale of a month was chosen, rather than one year, so as to provide a finer temporal scale. The model calibration was made using data from official government records, the bulk of which was freely available online, as well as from several United Nations and other international or regional agencies involved with research or projects on trade, development, environmental protection or social welfare [16]-[19]. This base time for calibration was January 1985 and the end in December 2014. Most of the model is built with quantitative data, but the social and the welfare modules attempt to also incorporate qualitative data.

\subsection{Model Structure}

\subsubsection{The Environmental Module}

\section{1) Land use}

The land use module focuses on land use changes. Three categories of land use were considered: 1) forest land; 2) palm tree plantations; 3) other agricultural land. Their respective datasets were found from FAO Data [20] and the Malaysian Department of Statistics [21]. Land cover may switch from one category to another depending on the parameters of the global model. Palm oil plantations were divided into 4 crop stage classes

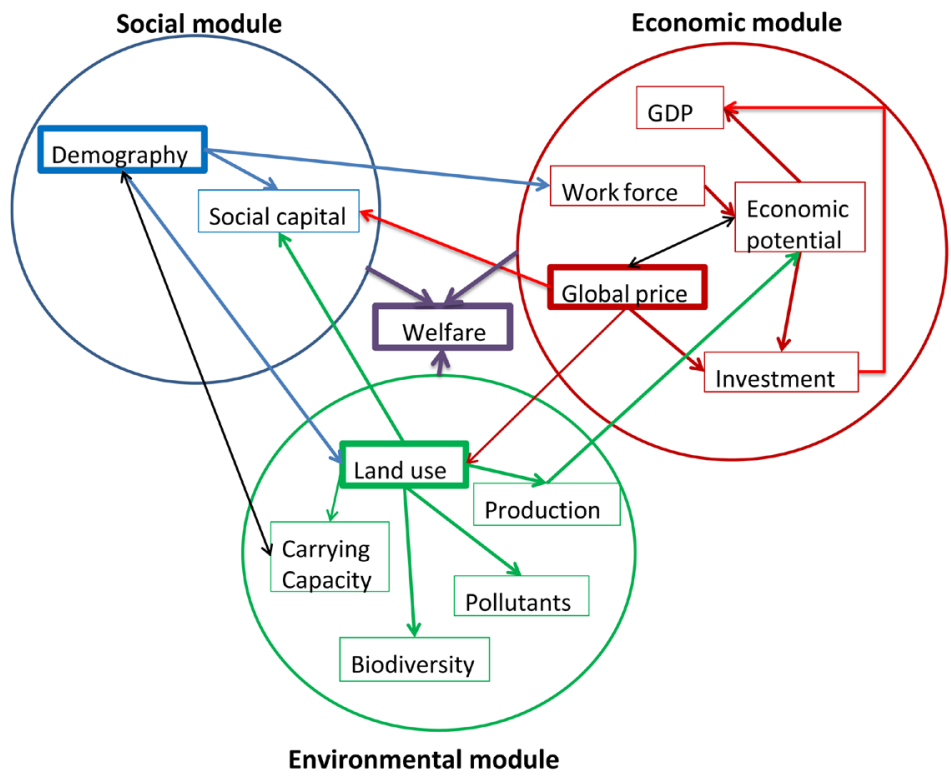

Figure 1. Global model structure showing the three main modules: Environment, Economy and Social development or welfare. Welfare is at the interface of these three modules. Stocks in bold face were expected to show greatest influence in the whole model dynamic. 
corresponding to the annual productivity values of the 4 fresh fruit bunches (FFB) [22]. These productivity values were converted to monthly portions for ease in incorporation into the model's temporal component of monthly steps. The total productivity was obtained by summing up the productivity of each crop-stage class, FFB productivity was then converted into crude palm oil production (CPO) by using a CPO yield of $21 \%$ of FFB production [22]. After 30 years, the palm trees are usually cut and new palm trees are planted.

The main drivers of land use change appeared to be the human population and the palm oil market price, based on the predictive model: PoTC $=\alpha * \mathrm{P}_{\mathrm{M}}+\beta \mathrm{P}_{\mathrm{H}}$, where PoTC is total palm tree plantation cover; $\mathrm{P}_{\mathrm{M}}$ is market price; and $\mathrm{P}_{\mathrm{H}}$ is human population $\left(\mathrm{R}^{2}=0.99, p=0.043\right)$. As a way of calibrating the model for this particular module, the coherence of the model was tested against actual observation (existing datasets) by for instance randomly and progressively increasing plantation cover with values between 5000 and 20,000 ha and reducing it gradually with values between 60,000 to 5000 ha. Land allocated to new palm tree plantations constituted $40 \%$ of total land allocated by Malaysia to all crop-based agriculture and is also equivalent to $60 \%$ of forest total natural forest cover. However, as a deliberate rule, when palm oil market price fell to less than US $\$ 100$, the model assumed that the plantations were abandoned. This is because existing datasets showed that this price was the lowest average during the period in consideration.

\section{2) Biodiversity}

The biodiversity paramere focused on the population dynamics of tigers and orang-utans, because the survival of these two iconic and endangered species is intimately linked to the preservation of forests [23] [24]. The dynamics of each population is based on the forests capacity to support species food, dispersal and reproductive needs as well as resilience against poaching pressure parameters. The survival of each species depends on a large enough territory and a sufficient amount of food within this range, specifically other mammals and fruit trees, respectively [16] [25]. The quantities of each type of food together with the size of the territory available were directly calculated from forest cover. At each time step, the maximum number of individuals that the environment could support was estimated by the model. During periods when forests are not under stress for the requirements of resident animal/biodiversity populations, the animals' reproduction rates increased while mortality decreased, and vice versa. In addition to natural death, the poaching parameter puts anthropogenic pressure on both species. Poaching was negatively correlated to the Malaysian economic performance since subsistence or commercial poaching was consequence of reduced gross domestic product per capita (GDP) during economic depression periods, and forest-neighbourhood communities resort to poaching for alternative sustenance.

\section{3) Pesticides and fertilizers}

Total pesticides and fertilizers applied are calculated using on empirical equations with actual datasets from annual statistics of the Malaysian Government [16]. These two parameters, that were essentially environmental pollutants due to their inorganic nature, were directly linked to the environmental quality index in the welfare module, i.e. their long-term use reduces environmental quality. Further, GDP in the economics section directly linked to total volumes of pesticides and fertilizers applied, such that increases in the GDP in economic boom periods indirectly enabled farmers to apply more fertilizers and pesticides, perhaps even more chemically potent ones, further degrading the environment. This degradation was calculated overall based on the Rander's approximation model of decomposition, photodecomposition and biological metabolism [26]. The complex process is represented by an exponential decay with the half-life degradation in soil. According to Rander, DDT's half-life for instance can range from 3 years to 30 years. However, in adapting this for purposes of the model, our overall average for a combined ranges for pesticides and fertilizers, however, were three and one month, respectively [16].

\section{4) Land carrying capacity}

The aim of this parameter was to evaluate the human carrying capacity, defined as the number of individuals that the local resources can support, in particular, considering food supply (average total kilocalories per individual) [27]. The availability of food is influenced mainly by two factors, namely total non-palm oil consumptive crop-based agricultural as well as livestock production, including fishing and other aquaculture, all considered only at the national level (excluding international inflows or outflows). These fundamentally depend on total land area devoted to agricultural activities. This land area is represented by the "Other Agricultural Cover" within the Land-use sub-component of the Environmental Module (Figure 2). Based on the existing official datasets [16] [28], it was possible to identify the average breakdown of the various types of farming (permanent crops; arable lands; etc.) and livestock (cattle, sheep, poultry, pig, fish, etc.). Additionally, using the average values of yield per hectare of agricultural products and the feed conversion ratio (a measure of an animal's efficiency in converting feed 


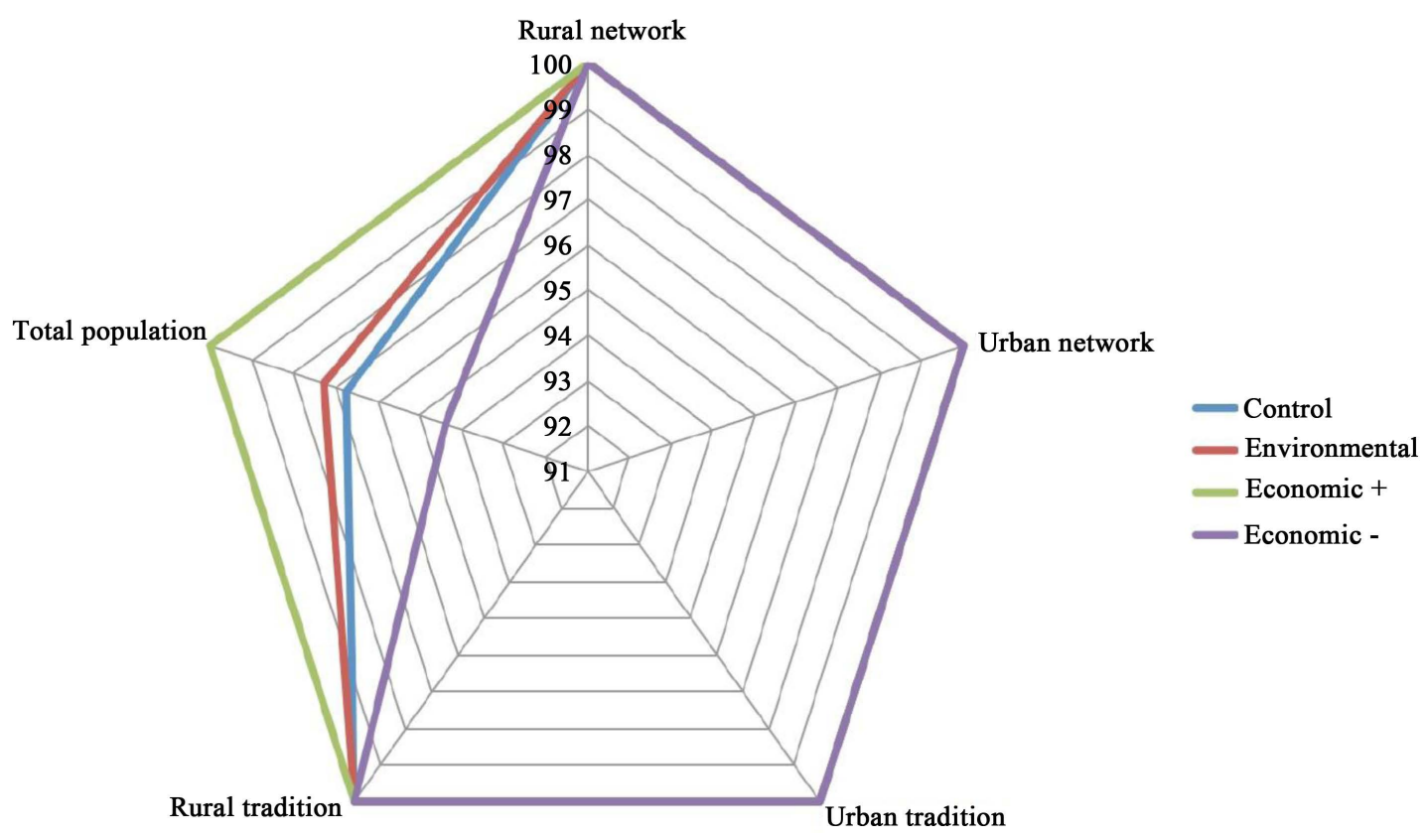

Figure 2. Relative final parameter values for each scenarios within the Social module.

mass into increases of the desired output [29], it was possible to connect hectares of land under agricultural production to food production for human population and animals. Finally, the rate of consumption of animal feeds and human food was also linked to the quantity of waste produced and recycling or other application of these. This is itself influenced by literacy levels of the population, represented as an alphabetization index within the Welfare module.

\subsubsection{The Economics Module}

\section{1) Palm oil market price}

The Market price was taken to be the price at which the palm oil is sold on the global market. This value, alternatively called global price, has a huge impact on the management decision: if the price is high, more palm oil tree will be planted and vice versa. It involves the world demand, which we fixed in our model for testing the various scenarios. To calculate the demand, we took in consideration the price elasticity of demand, which represents the percentage change in quantity demanded in response to a unit change in its price [30] [31]. In the model, the palm oil market price was directly interacted with total palm oil production taken from the environmental module.

\section{2) Alternative capital}

This portion of the Economics Module represented the proportion of agricultural production which constitutes the alternative source of export in the absence of palm oil farming [32]. In the model, the Alternative Capital stock was connected to a bi-flow, which corresponded to alternative agricultural production segments (agricultural alternatives to palm oil). This was derived from total agricultural products, excluding palm oil, multiplied by the average price per tonne, resulting in total alternative agricultural earnings. This input, therefore, changes depending on the Market Price of palm oil. When palm oil price reduces, total alternative agricultural production investment increases [33], leading to a corresponding increase in alternative capital. Thus, alternative capital and palm oil price should be inversely proportional. When the palm oil price changes in terms of percentage, it induces a change in alternative agriculture products [34] [35]. The key outflow from the alternative agricultural earnings is the Sales Tax charged by the government before export [36]. Externally, this parameter is connected to the Market Price and the GDP parameters.

\section{3) Gross Domestic Product}

In general, Gross Domestic Product is the monetary measure of total final goods and services produced in a country for one a year, or any other time period. In this case we considered the Nominal GDP, that is, excluding production that flowed into Malaysia emanating from other countries, except from export earnings from goods and 
services produced in Malaysia. In the case of the present model, it was considered monthly, and measured in US dollars. The inputs for this parameter were the oil exports from the Oil potential and the alternative agricultural earning coming from the Alternative capital. GDP per capita was obtained by weighting GDP on the total human population, which was part of the Social module, all of which were also sourced from Perspective Monde [17]. While GDP was used as per capita in the Social module, it was used as GDP stand-alone input in the Environment module. Overall, GDP is the best definer for the state of the economy, throughout the present modeling and simulations.

\section{4) Economic potential}

Economic potential represents the total revenues earned from palm oil in Malaysia both from domestic and from export markets. It therefore contributes to the overall GDP but apart from this also spurs Investment in other agricultural or non-agricultural ventures domestically, and support or accounts for the palm oil Workforce inflows/outflows. The workforce here may be divided into two components: 1) workers in palm oil industry alone; 2) total number of workers nationally.

\subsubsection{The Social Module}

\section{1) Tradition and network relations}

The aim of this parameter was to account for impact of palm oil production on the social structures of the Malaysian communities [12]. The social capital was constructed as the sum of two stocks: 1) agriculturally related traditions such as land rights and perception of agricultural practices; and 2) social linkages. These stocks are interconnected: a group with strong social links is more able to establish shared traditional values [11]. We made a distinction between urban and rural population for two reasons. The first is the assumption that the rural population would be economically directly impacted by palm oil production and deforestation [37]. The second is the gap between the rural population and urban population in terms of traditions, culture and economic situation in Malaysia [38]. This traditions and networks module had some interactions in the model, with some inputs from some parameters within the Environmental, Welfare and Economics modules. The final output from the Social module was Social capital which, was fed into the Welfare module.

The social network parameter was assumed to be positively influenced by such social interaction issues as family structure, the media and internet. This is because family structure is the bridge between individuals and society. It is also the tool used for transmission of traditions, values and knowledge. Media and the internet not only contribute to maintenance of linkages between members of a community or across communities but also is are a source of new ideas, and play increasing crucial roles in Malaysia just as in all counties of the world [39]. For instance, new knowledge, skills and ideas acquired either form schools, the media or internet, coupled with economic challenges in rural areas can trigger migration to urban areas, in the process, not only breaking family units but possibly also changing attitudes to farming methods and traditional values.

\section{2) Human population}

In this paramere the whole population of Malaysia was divided into 5 age groups: 0 to 14,15 to 17,18 to 45 , 46 to 64 and 65 years or more, since these age-groups play different roles in Malaysian society. Each group was further divided into urban and rural components. The initial value of each age group was given by an estimation based on World Bank Group statistics (35). We standardized the birth and death rates for all population components, for simplicity in calculations and model testing. The only inflow was birth, itself related GDP per capita from the Economics module, as well as the human carrying capacity in the Carrying capacity sub-component of Environmental module. We disregarded emigration and immigration here, because according to the data from the World Bank Group [40], its influence on the total population of Malaysia was not significant over the period under consideration.

\subsubsection{The Human Welfare Module}

The aim of this module was to assess effects of the palm oil production on the welfare of the Malaysian population, considering two different population categories, urban and rural. It was estimated by integrating four different indices: environmental quality, health standards, standard of life, and overall life satisfaction. Each of these indexes aggregated many indicators with thresholds used to qualify quantitative data, which was expressed on an appreciation scale from 1 to 5 (worst) where 1 (best). The indicators were standardized in order to give greater weight to those having stronger linkage with the palm oil production. The weighting went from 1 (weakest) to 3 (strongest linkage). The inputs into this module came from the environmental module (forest cover, iconic wildlife 
species and fertilizers and pesticides in soil), the economics module (total cover of palm oil, monthly production and GDP per capita), the social module (social capital and total population), and human carrying capacity parameter. The other indices and thresholds were built following IAURIF [41] and UNDP [42] data sets about human development, as well as additional data from the IMF [43] and WWF [44]. Simultaneous to these indicators, another index was built (local palm oil index) which included only indicators related to the palm oil production in order to increase the sensitivity of the global model towards the palm oil production fluctuations.

\subsection{Modeling Projected Scenarios}

While the model was calibrated and tested with data obtain for a period of 30 years from January 1985 to December 2015, the projections simulations were for the ten year period from 2014 to 2024. Simulation projections revolved around four main scenarios: a Control; Environmental Improvement; Economic Growth; and Economic Decline. In the first scenario, Control, trends follow initial calibration with no changes in any parameters in any way. In the Environmental scenario, we biased the focus on forest cover size and biodiversity protection both of which should benefit from decreased use of pesticides and fertilizers as well as lower generation of waste. The economic growth scenario (Economy (+)) hinged by an increased world demand for palm oil spurring an increased effort in palm oil production. The final scenario, economic decline (Economy $(-)$ ), was associated to the contrary i.e. a steep decrease in global demand for palm oil resulting in lower palm oil cultivation or production (Table 2).

\section{Results}

For each module and for each scenario the modeling simulation was able to expose how various parameters evolved as well as the final states of the component modules and parameters at end of the projection period for each scenario. For each simulation results (Figures 2-5), relative final parameter values correspond to percentage of the maximum value reached for each parameter in the four scenarios. The highest value reached by each parameter during the 4 scenarios is set at $100 \%$.

Table 2. Results of model simulation run showing parameter values reflecting projections under each of the four scenarios. Note: POP = Palm Oil Production; GDP/C = GDP per capita.

\begin{tabular}{|c|c|c|c|c|}
\hline Parameter & Control & Environmental protection & Economic growth & Economic decline \\
\hline Farm workers/ha & 3.5 & 3.5 & 2 & 3.5 \\
\hline Other agriculture conversion to POP & 0.4 & 1 & 0.4 & 0.4 \\
\hline Forest conversion rate to POP & 0.6 & 0 & 0.6 & 0.6 \\
\hline Tiger poaching pressure & $\begin{array}{c}\text { If high GDP/C } \\
\text { THEN 2; If low } \\
\text { GDP/CTHEN 7; } \\
\text { Else } 5\end{array}$ & 1 & $\begin{array}{c}\text { If high GDP/C } \\
\text { THEN 2; If low } \\
\text { GDP/C THEN 7; } \\
\text { Else } 5\end{array}$ & $\begin{array}{c}\text { If high DP/C } \\
\text { THEN 2; If low } \\
\text { GDP/C THEN 7; } \\
\text { Else } 5\end{array}$ \\
\hline Orangutans poaching pressure & $\begin{array}{l}\text { If high GDP/C } \\
\text { THEN 30; If low } \\
\text { GDP/C THEN } \\
\text { 50; Else } 40\end{array}$ & 20 & $\begin{array}{l}\text { If high GDP/C } \\
\text { THEN 30; If low } \\
\text { GDP/C THEN } \\
\text { 50; Else } 40\end{array}$ & $\begin{array}{c}\text { If GDP/high } \\
\text { THEN 30; If low } \\
\text { GDP/C THEN 50; } \\
\text { Else } 40\end{array}$ \\
\hline Total pesticides applied (tonnes/ha) & 1 & 0.1 & 2 & 0.5 \\
\hline Total fertilizers applied (tonnes/ha) & 1 & 0.1 & 2 & 0.5 \\
\hline Human death rate & $\begin{array}{l}\text { Rural: } 4.7 * 10^{-4} \\
\text { Urban: } 4.5 * 10^{-4}\end{array}$ & $\begin{array}{l}\text { Rural: } 4.2 * 10^{-4} \\
\text { Urban: } 4.0 * 10^{-4}\end{array}$ & $\begin{array}{l}\text { Rural: } 4.3 * 10^{-4} \\
\text { Urban: } 4.2 * 10^{-4}\end{array}$ & $\begin{array}{l}\text { Rural: } 4.95 * 10^{-4} \\
\text { Urban: } 4.85 * 10^{-4}\end{array}$ \\
\hline Production rate & Fixed value & Fixed value & Increase $0.1 \%$ & Decrease $0.1 \%$ \\
\hline Feed conversion Rate & Fixed value & Fixed value & Decrease $0.3 \%$ & Increase $0.3 \%$ \\
\hline Fishing & Fixed value & Fixed value & Increase $0.2 \%$ & Decrease $0.2 \%$ \\
\hline Waste generation rate & 0.3 & 0.1 & 0.3 & 0.3 \\
\hline World demand (metric tonnes) & 300,000 & 300,000 & 600,000 & 100,000 \\
\hline
\end{tabular}




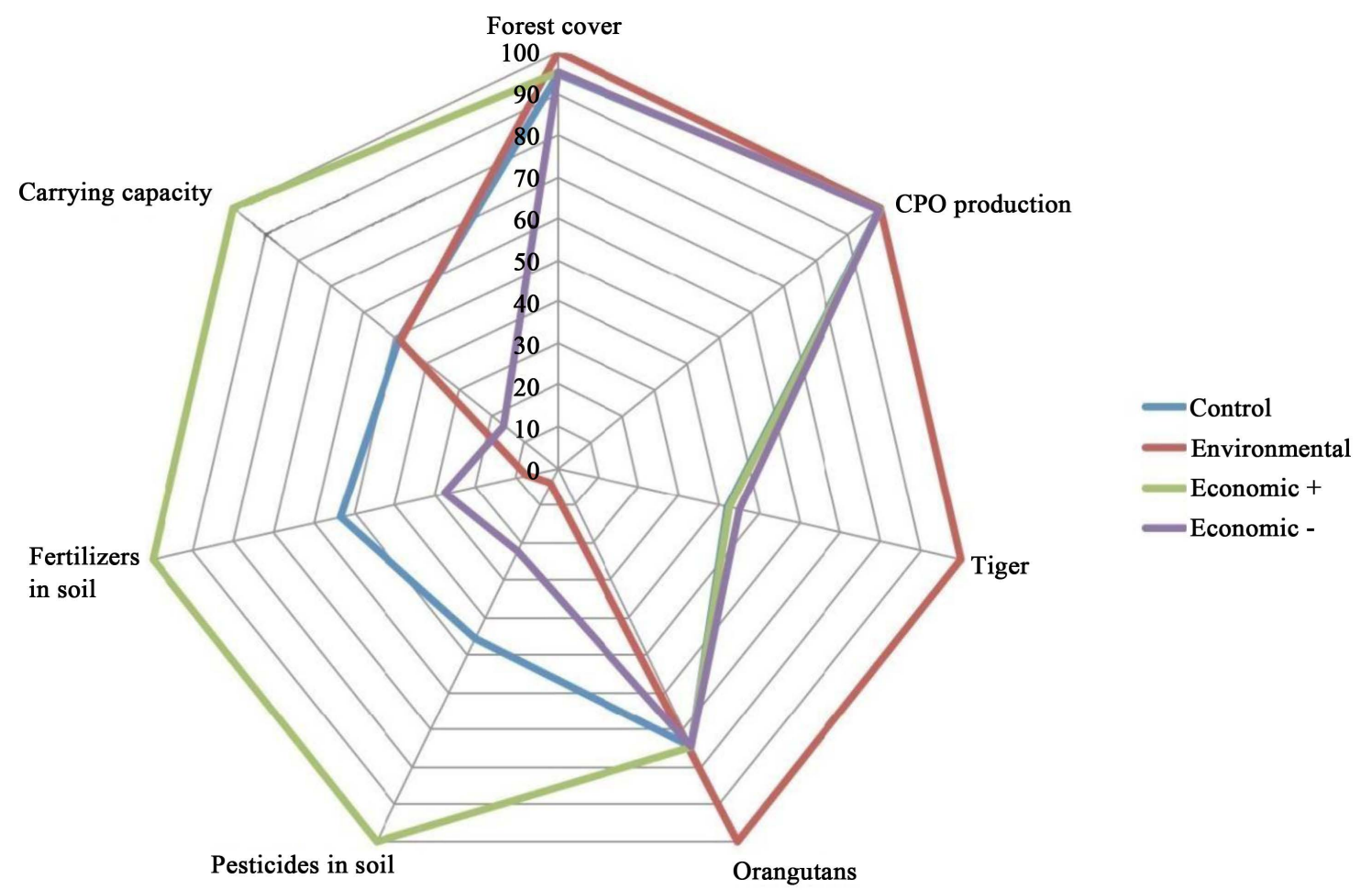

Figure 3. Relative final parameter values for the different scenarios within the Environmental module. CPO = overall palm oil production.

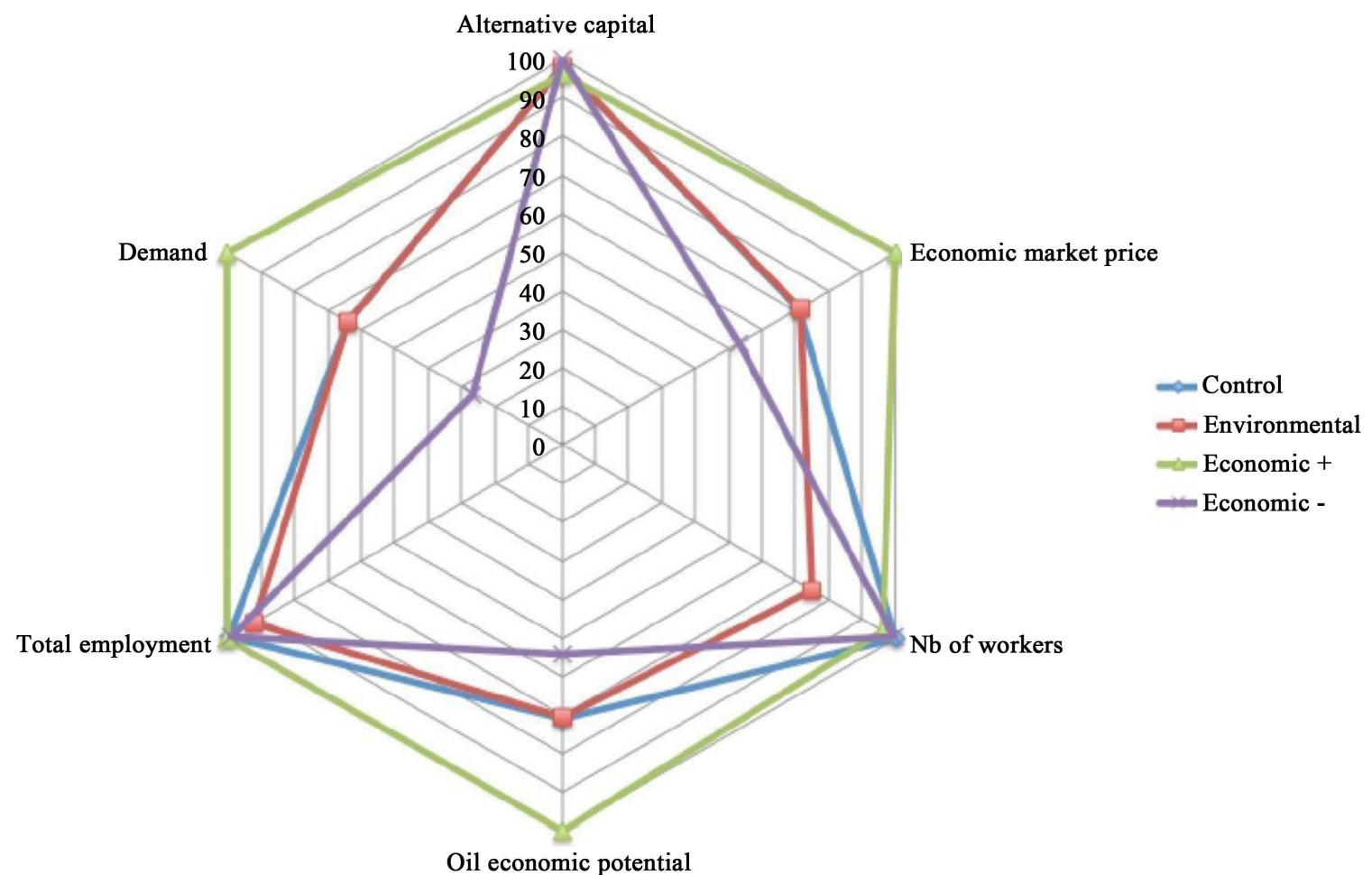

Figure 4. Relative final parameter values for the different scenarios within the Economics module. The Global Price component is decomposed into economic market price and the global demand while Workforce into workers in palm oil industry and total number of workers nationally. 


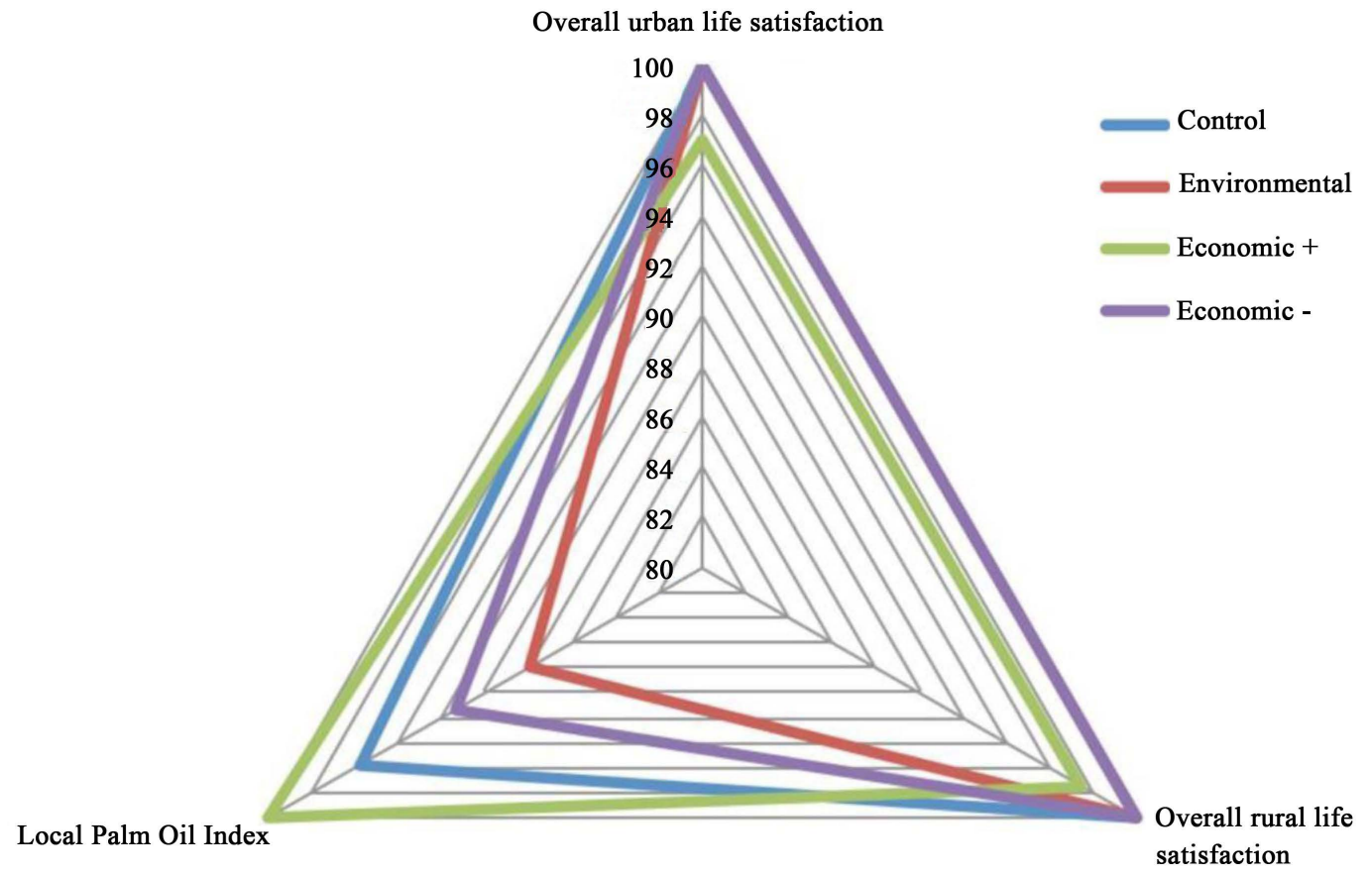

Figure 5. Relative final parameter values for the different scenarios within the welfare module.

\subsection{The Social Module}

The total human population increases in all scenarios, with the increase remarkably identical similar for the Control and the Environmental conservation scenarios. However, the population increases more rapidly in the Economic growth (Economy $(+)$ than in the Economic decline (Economy $(-)$ scenario (Figure 2)). Social network and traditions display exactly the same trends regardless of the scenarios. Tradition in urban and rural communities together with the social network in urban population increases regularly and also presents identical values while the social network of rural population is rather constant. Except for total human population, indicators in social module generally do not differ regardless of scenario. The deviation in population between Economic (-) and Economy $(+)$ at the end of the simulation is considerable, standing at 2.2 million people.

\subsection{The Environment Module}

The quantities of fertilizers and pesticides in soils show discrepancies between scenarios. For instance pollutants are highest in Economy $(+)$ followed by Control then Economy $(-)$. The Environmental conservation scenario corresponds to the most significant decrease in pollutants. However, forest cover and abundance of iconic species (tigers and orangutans) appeared to decrease in all scenarios, with Environmental conservation scenario being the only one capable of decelerating this decrease in forest cover and biodiversity loss. Palm oil production presents the same increasing trends in the different scenarios, showing its resilience as well as the nation's strong dependence on it for future development aspiration both at the at the domestic as well as international level. Carrying capacity shows contrasting evolutions: while it is roughly unaffected by or shows no response under Control and Environmental conservation scenarios, it suddenly increases under improved economic performance (Economy $(+)$ ) but decreases sharply and linearly under economic decline or Economy $(-)$, suggesting it may be deliberately increased to spur economic growth.

Environmental conservation scenario is the best option for reducing environmental pollutants, the preservation of important biodiversity (iconic species) and the maintenance of forest cover (Figure 3). The three other scenarios increase pollution levels and decrease the number of iconic species. The Economy $(+)$ scenario is the most significantly associated to increased use and application of fertilizers and pesticides and the Control scenario is related to the high rates of forest loss as is Economy (+). Only Economy (-) shows reduced pressure on less of forest cover. The final value for palm oil production is similar regardless of the scenarios, again demonstrating 
palm oils overall significance in Malaysia now and in the future. Carrying capacity shows a deviation of 46 million inhabitants between the two Economic scenarios, with Economy $(+)$ supporting the most inhabitants. The two other scenarios are almost the same and intermediary (see Figure 3).

\subsection{The Economics Module}

Palm oil market price shows a clear variation through the different scenarios. It increases in the Economy (+) scenario but understandably decreases in the other three, the most rapid decrease being observed for the Economy (-) scenario. On the other hand, global demand for palm oil shows composite and heterogeneous responses, with slow increases in Control and Environmental conservation scenario, sharper increases under a favourable economy (Economy + ) but decrease when the economy slumps under Economy (-) (see Figure 4).

The number of workers needed to work palm oil farms declines only in the Environmental conservation scenario but remains constant under all other scenarios (Figure 4). However, the total number of people employed increases linearly in all scenarios but at a much slower rate, and is in fact lowest under the Environmental conservation scenario. For palm oil economic potential, three types of behaviors are observed: a constant trend through lower value for the environmental conservation and control scenarios, a rapid increase under Economy $(+)$ and a decrease under Economy (-). Alternative capital increases under Economy (-), Control and Environmental conservation scenario but is slightly lower under Economy $(+)$. As Figure 4 shows, all parameters reach their highest final values in the Economics $(+)$ scenario with only the alternative capital attaining nearly the same final value in all four scenarios.

The palm oil market price differs by up to 182 USD/ton between the two economics scenarios, and the final price values in the Environmental conservation and Control scenarios are generally similar. Under control scenarios, the highest parameters are numbers of workers in palm oil farming and the total number of employees in the entire palm oil sector.

\subsection{The Welfare Module}

Despite the usually higher incomes for urban dwellers, the overall life satisfaction of urban and rural communities appears to be nearly comparable, under both favourable and unfavourable economic scenario (Economy + and Economy -). This is presumably due to socio-economic challenges in urban settings, including loss of tradition values and social units, as compared to the rural areas. However, both rural and urban welfare indices perform slightly worse under Economy + than under Economy (-) scenarios. The local palm oil index increases in all scenarios but reaches the highest value under Economy $(+)$ scenario, followed the Control and Economics $(-)$ but is lowest under the Environmental conservation scenario, showing that environmental health is significantly compromised when emphasis is laid on maximizing palm oil production. By contrast, life is most satisfactory in both rural and urban settings when environment is most preserved (Figure 5).

\section{Discussion}

\subsection{Main Observation from the Projected Scenario}

Results of model simulations for future projections indicated that within the social realm, social systems amongst Malaysia's citizens, such as networks and traditions thrive best in the rural areas regardless of any scenario. On the other hand, in urban areas, social systems are tend to be sustainable only under relatively low economic performance but are otherwise irrelevant under any other scenario. Further, under a depressed economy scenario, total human population size reduces, possibly due to increased mortality, especially since the population rises considerably under economic prosperity scenarios. Impact of economic performance on population size is so profound that there occurs a 2.2 million difference between favourable and unfavourable economic performance.

Within the economics module, a scenario of positive economic is consistent with high global demand for palm oil and higher market price which actually implies that attractive sales prices lead to increased export volumes that benefit the economy from foreign exchange earnings. This also ultimately spurs investment in palm oil production thereby boosting the palm oil sector's contribution to the economy (Figure 4). Under such high volumes of export of palm oil, employment opportunities are also created, both in palm oil sector and at the overall national level, re-affirming the commodity's significance (palm oil potential) in Malaysia's current and future economic performance (Figure 4). 
However, increased numbers of workers due to better economic growth, particularly from palm oil sector revenues, is associable to environmental degradation and loss of biodiversity as natural forest cover shrinks due to clearance to create more palm oil fields to absorb the labour force and to create increased carrying capacity to settle more people. Such a process also exposes wildlife to increased poaching rates. Application of agrochemicals, including inorganic fertilizers, appeared to be the most serious driver of environmental degradation, whether the economy has positive, negative growth or remains unchanged. These are presumably variables that have either direct negative effects on soil health but also act as indirect confounding variables through increased total agrochemicals applied due to more newly-cleared forests, and more workers employed in the sector. Therefore, although palm oil production index appears maximal under a growing economy, unmitigated exploitation of the land for palm oil export would result into considerable environmental degradation in the long run.

Economic performance and environmental conservation showed further variant implications for overall social welfare of the Malaysian citizenry. For instance overall satisfaction, rural or urban appears unchanged whether the economy should do well or poorly. This may due to the fact that GPD, the main definer of economic performance in this model, was calculated per capita, regardless of these two population segments. On the other hand, only rural dwellers appear to benefit from social satisfaction as a result of or under a well conserved environment scenario. This may be a result of reduced infections or pollution, enjoyment of benefits of biodiversity including outdoor recreation, and even revenues from nature-based tourism which may boost rural incomes but make insignificant impact on urban dwellers.

In all, environmental conservation and care presents the best future prospect for sustainable palm oil economy in Malaysia since only in such a scenario can there be an optimal balance between palm oil production, favourable economic growth as well as better preservation of biodiversity and increased overall social welfare under a modest human population growth regime

\subsection{General Evaluation of the Model's Performance}

The model performed quite well in overall, with outputs consistent with expectations from the inputs within the three main modules. Not only were there numerous variables with complex interactions amongst them but also various patterns of linkages between the modules. In spite of its complexity, the graphical outputs of the model successfully portrayed the underlying equations linking its various simulatively interactive parts in a responsive way. The model was also sensitive to scenario changes (control; favourable environmental conservation policy; economic growth; economic decline), especially when key variables that significantly influenced interactions were modified. Thus it was easy to observe that forest cover, palm oil market price and perhaps total population of Malaysia, are the greatest drivers of palm oil production focus, in conjunction with world demand.

Sensitivity was largely localized rather than global/total, such that only a few parts or variables (such as market price mentioned above) are responsible for its outcomes under various scenarios. Most of the other variables are largely latent and do not trigger any significant overall outcomes even if the values are modified. Examples are population birth rates, biodiversity, environmental pollution or labour force. This apparent limitation in interactive sensitivity may, in part, be due to connections between variables that have little actual effects on each other. It could also be a lack of adequate information about how the different variable elements interact in the Malaysian palm oil production system. For instance, it is possible that when analysed on a monthly basis, birth rate is not effectively additive to GDP, or monthly loss of species is less connected to standard of living that is usually evaluated in time steps longer than one, at times even 5 years. This makes the model divert away from possible intuitive expectations in reality. Moreover, apart from the world demand for palm oil, modules are only influenced by factors within Malaysia while in reality there are many other international variables, such as climatic or regional weather hazards, or political changes that might affect palm oil production systems, policies and trends [45]. Changing values of parameters within parameters rather than making true dynamic links in scenario building further undermined the overall performance of the model and made it vulnerable to total loss in case of system failure (crash). In spite of all these, the model performed well enough to actualize the general linkages amongst key sets of variables selected as envisaged. It also provided a remarkably effective and fairly actionable decision tool for understanding the interactions amongst environmental, economic and social aspects in Malaysia with regard to future forecast in palm oil production. The results therefore offer an important technical background for policy pro-action towards pursuit of an effective balance between agricultural productivity and environmental conservation for sustainable development in emerging and other developing economies such as Malaysia. 


\subsection{Conceptual Limits and Assumptions of the of Model}

The simulated projections by the model assumed that land cover dynamics are controlled primarily by two main factors: palm oil price and total human population, and that land cover parameters are restricted to three main types of land cover: palm oil, forest and other (non-palm-oil) agricultural lands. Similarly, population dynamics (human or animal) were considerably oversimplified. For instance, human death rates were also assumed to be equal for all age classes meaning that the chance to die young or old is similar. Malaysian population was divided into rural and urban communities but was modeled as a whole and do not include migrations and interactions between the former population segments. Life standard in the welfare parameter was calculated based on the unit market price of palm oil such that lower prices induce higher life standards. Although this may intuitively hold true given the significance of palm oil in Malaysia's economy, not every segment of the population derives livelihood from palm oil revenues, nor do foreign exchange earnings from national palm oil export necessarily benefit entire populations in an equitable or measurable way. Further, the labor force included all people working full time in the palm oil industry between the ages of 15 and 65 regardless of excluding health occasional health problems, handicaps or inter-sector labour mobilities. In addition it was assumed that all palm oil produced is exported and that there will be no influences of adverse weather, technological changes, industrial actions or seasonal disruptions to affect production targets. In reality, though, a substantial proportion of the commodity may be consumed domestically, while poor weather (due to changing climate), worker strikes or invasive pests may contribute substantially to missed production targets during some coming years. Therefore in overall, more stringent and detailed parameter calibrations to address these limitations would significantly improve the model's performance.

\section{Conclusion}

It is clear that the main modules selected for the simulations, as well as their component variables are interrelated enough to affect each other when changes are imposed both in the short and the medium term. For future projections in particular, scenarios and variable interactions that reduced environmental damage would offer the best chance for optimizing the palm oil economy while also minimizing forest loss and promoting citizen social welfare.

\section{Acknowledgements}

We give great thanks to the University of Quebec at Trois-Rivieres for providing funding under the UQTR Foundation Funds scheme for the modeling project during the 2014 Environmental Systems Analysis Modeling Winter School; the University of Quebec at Montreal for arranging all logistics and facilities; Annick Gelinas for great support through additional sessions on Modeling Language while in Montreal; and to my project advisors Giliano and Jean-Claude Montana for the initial reviews of the manuscript.

\section{References}

[1] World Population Review: Malaysia Population. World Population Prospects—Global Demographic Estimates and Projections by the United Nations. http://worldpopulationreview.com/countries/malaysia-population/

[2] Anand, S. (1977) Aspects of Poverty in Malaysia. The Review of Income and Wealth, 23, 1-16. http://dx.doi.org/10.1111/j.1475-4991.1977.tb00001.X

[3] Basiron, Y.A.C.K.W. (2004) The Oil Palm and its Sustainability. Journal of Oil Palm Research, 16, 1-10.

[4] World Growth (2011) The Economic Benefit of Palm Oil to Indonesia; Palm Oil Green Development Campaign Report. http://worldgrowth.org/

[5] Basiron, Y. (2007) Palm Oil Production through Sustainable Plantations. European Journal of Lipid Science and Technology, 109, 289-295. http://dx.doi.org/10.1002/ejlt.200600223

[6] Lai, O.M., Tan, C.P. and Akoh, C.C. (2012) Palm Oil-Production, Processing, Characterization, and Uses. AOCS Press, Urbana, Illinois, 211-233.

[7] Corley, R. (2009) How Much Palm Oil Do We Need? Environmental Science and Policy, 12, 134-139. http://dx.doi.org/10.1016/j.envsci.2008.10.011

[8] Food and Agriculture Organization (2008) FAO Statistics: Crop and Livestock Products. http://faostat.fao.org/

[9] Lim, K.Y. (2010) A Call to Arms: To Defend Palm Oil. Global Oils and Fats Business Magazine, 7, 9-11.

[10] Oxford Business Group (2011) Economic Update. Malaysia: Oiling the Economy. 
http://www.oxfordbusinessgroup.com/economic_updates/malaysia-oiling-economy

[11] Costanza, R., Wainger, L. Folke, C. and Mäler, K.G. (1993) Modeling Complex Ecological Economic Systems. BioScience, 43, 545-555. http://dx.doi.org/10.2307/1311949

[12] Patterson, T., Gulden, T., Cousins, K. and Kraev, E. (2004) Integrating Environmental, Social and Economic Systems: A Dynamic Model of Tourism in Dominica. Ecological Modelling, 175, 121-136. http://dx.doi.org/10.1016/j.ecolmodel.2003.09.033

[13] Koh, L.P. and Wilcove, D.S. (2008) Is Oil Palm Agriculture Really Destroying Tropical Biodiversity? Conservation Letters, 1, 60-64. http://dx.doi.org/10.1111/j.1755-263X.2008.00011.x

[14] Fitzherbert, E.B., Struebig, M.J., Morel, A., Danielsen, F., Brühl, C.A., Donald, P.F. and Phalan, B. (2008) How Will Oil Palm Expansion Affect Biodiversity? Trends in Ecology and Evolution, 23, 538-545. http://dx.doi.org/10.1016/j.tree.2008.06.012

[15] Fargione, J., Hill, J., Tilman, D., Polasky, S. and Hawthorne, P. (2008) Land Clearing and the Biofuel Carbon Debt. Science, 319, 1235-1238. http://dx.doi.org/10.1126/science.1152747

[16] Azlan, J.M. (2006) Mammal Diversity and Conservation in a Secondary Forest in Peninsular Malaysia. Biodiversity \& Conservation, 15, 1013-1025. http://dx.doi.org/10.1007/s10531-004-3953-0

[17] Université of Sherbrooke (2014) World Perspectives on Malaysia. Perspective Monde. http://perspective.usherbrooke.ca/bilan/servlet/ComprendreContextePIB?codePay s=MYS\&annee=1985

[18] Index Mundi (2015) Palm Oil Exports by Country in 1000 MT. United States Department of Agriculture. http://www.indexmundi.com/agriculture/?commodity=palmoil\&graph=exports

[19] Index Mundi (2015) Palm Oil Monthly Price-US Dollars per Metric Ton. http://www.indexmundi.com/commodities/?commodity=palm-oil\&months=360

[20] Food and Agriculture Organization (2010) Country Report: Malaysia. Global Resources Assessment for 2010. Rome. http://www.fao.org/forestry/fra/en/

[21] Department of Statistics of Malaysia (2015) Statistics Compilation: Official Government Portal. http://www.statistics.gov.my

[22] Butler, R.A., Koh, L.P. and Ghazoul, J. (2009) REDD in the Red: Palm Oil Could Undermine Carbon Payment Schemes. Conservation Letters, 2, 67-73. http://dx.doi.org/10.1111/j.1755-263X.2009.00047.x

[23] Greenpeace (2013) Licence to Kill. How Deforestation for Palm Oil is Driving Sumatran Tigers toward Extinction. Greenpeace International, Netherlands, 5-20.

[24] Soehartono, T. (2007) The Strategy and Action Plan for Conservation of Indonesian Orangutan. Directorate General of Forest Protection and Nature Conservation, Ministry of Forestry. http://www.orangutan.org.uk/blog/2007/12/12/action-plan-for-nationalconservation-of-orangutans-launched-in-bali/

[25] Galdikas, B.F. (1988) Orangutan Diet, Range, and Activity at Tanjung Puting, Central Borneo. International Journal of Primatology, 9, 1-35. http://dx.doi.org/10.1007/BF02740195

[26] Ford, F.A. (1999) Modeling the Environment: An Introduction to System Dynamics Models of Environmental Systems. Island Press, Washington DC.

[27] Hopfenberg, R. (2003) Human Carrying Capacity Is Determined by Food Availability. Population and Environment, 25, 109-117. http://dx.doi.org/10.1023/B:POEN.0000015560.69479.c1

[28] Food and Agriculture Organization (2014) Malaysia Agriculture. FAOSTATs. http://faostat.fao.org/

[29] Food and Agriculture Organization (2012) Animal Production and Health Proceedings Symposium: Optimization of Feed Use Efficiency in Ruminant Production Systems. Bankok, 27 November, 2010.

[30] Shariff, F., Rahman, A.K. and Amiruddin, M.N. (2006) The Elasticity of Foreign Demand for Malaysian Palm Oil. Oil Palm Industry Economics Journal, 6, 1-6.

[31] Rifin, A. (2010) An Analysis of Indonesia’s Palm Oil Position in the World Market: A Two-Stage Demand Approach. Oil Palm Industry Economics Journal, 10, 35-42.

[32] Hai, T.C. (2000) Land Use and the Oil Palm Industry in Malaysia. Abridged Report Produced for the WWF Forest Information System Database.

[33] Hassan, S., Othman, Z. and Karim, M.Z.A. (2011) Private and Public Investment in Malaysia: A Panel Time-Series Analysis. International Journal of Economic \& Financial Issues, 1, 199-210.

[34] Asari, F.F.A.H., Rahman, N.H.A., Razak, E.A.A., Ahmad, B.A.S., Harun, N.F.A. and Jusoff, K. (2011) A Time Series Analysis of the Relationship between Total Area Planted, Palm Oil Price and Production of Malaysian Palm Oil. World Applied Sciences Journal, 12, 34-40.

[35] World Wildlife Fund and Enviro Market (2012) Palm Oil Investor Review: Investor Guidance on Palm Oil for 2012. 
The Role of Investors in Supporting the Development of a Sustainable Palm Oil Industry, Report, $44 \mathrm{p}$.

[36] PKF Worldwide Tax Guide (2013) Malaysia Tax Guide 2013. www.pkf.com

[37] Hon, J. and Shibata, S. (2013) A Review on Land Use in the Malaysian State of Sarawak, Borneo and Recommendations for Wildlife Conservation Inside Production Forest Environment. Borneo Journal of Resource Science and Technology, 3, 22-35.

[38] Fau, N. (2013) The Singular Way of the Economic Development of the Malaysia. ELSA Lafaye of Micheaux, Malaysia, a Sovereign Development Model? Review of the Regulation. Capitalism, Institutions and Powers. https://regulation.revues.org/10055

[39] George, C. (2005) The Internet's Political Impact and the Penetration/Participation Paradox in Malaysia and Singapore. Media, Culture and Society, 27, 903-920. http://dx.doi.org/10.1177/0163443705057678

[40] The World Bank Group (2014) Data: International Stock Totals. http://data.worldbank.org/indicator/SM.POP.TOTL

[41] Institute of Development and Urban Planning in the French Isles Region (IAURIF) (2007) Strategic Sustainable Development Indicators: An Index of Quality of Life and Well-Being for the French Isles Region. http://www.iau-idf.fr/savoir-faire/nos travaux/edition/indicateurs-strategiques-de-developpement-durable.html

[42] United Nations Development Program (2013) Human Development Indicators and Thematic Tables. http://hdr.undp.org/fr/data

[43] The Echoes Data (2014) Malaysia. http://data.lesechos.fr/pays-indicateur/malaisie/tauxde-chomage.html

[44] World Wildlife Fund (2015) Palm Oil: Soil and Water Pollution. http://wwf.panda.org/what_we_do/footprint/agriculture/palm_oil/environmental_impacts/soil_water_pollution/

[45] Chachavalpongpun, P. (2013) The Politics of Palm Oil. Yale Global Online. The Whitney and Betty MacMillan Center for International and Area Studies at Yale. http://yaleglobal.yale.edu/content/politics-palm-oil 